\title{
PHYTOCHEMICAL ANALYSIS AND IN VITRO INVESTIGATION OF ANTI- INFLAMMATORY AND XANTHINE OXIDASE INHIBITION POTENTIAL OF ROOT EXTRACTS OF BRYOPHYLLUM PINNATUM
}

\author{
A. Latif ${ }^{*}$, K. Ashiq ${ }^{1,2}$, S. Ashiq ${ }^{3}$, E. Ali ${ }^{1}$, I. Anwer ${ }^{1}$ and S. Qamar ${ }^{4}$ \\ ${ }^{1}$ University College of Pharmacy, University of the Punjab, 54000, Lahore, Pakistan. \\ ${ }^{2}$ Department of Pharmacy Superior College, 17-km Raiwind Road Lahore, Pakistan. \\ ${ }^{3}$ Centre for Applied Molecular Biology, University of the Punjab Lahore, Pakistan. \\ ${ }^{4}$ Institute of Pharmaceutical Sciences, University of Veterinary and Animal Sciences Lahore, Pakistan. \\ Corresponding Author E-mail: abidalatif43@yahoo.com \\ https://doi.org/10.36899/JAPS.2020.1.0025 \\ Published online January 02, 2020
}

\begin{abstract}
The aim of present study is to emphasize the phytochemical and biological studies of root extracts of Bryophyllum pinnatum, as little work was documented on the roots. Phytochemical analysis of powder and extracts were evaluated by the standard methods. UV/ Visible scanning, FTIR and atomic absorption spectroscopy were also performed for the purposes of standardization. In vitro anti-inflammatory investigation was done by protein denaturation method and xanthine oxidase inhibition assay was performed to confirm anti-gout effect. Phytochemical analysis results revealed the presence of primary metabolites $(\% \mathrm{w} / \mathrm{w})$; carbohydrates $(48.54 \pm 0.6)>$ proteins $(21.06 \pm 0.6)>$ lipids $(1.32 \pm 0.001)$. Secondary metabolites $(\mathrm{mg} / \mathrm{g})$ were also isolated; methanol extract has higher concentrations of flavonoids $(95.81 \pm 0.026)$ and glycosaponins $(39.9 \pm 0.103)$ while in water extract polysaccharide $(139.4 \pm 0.026)$ and polyphenols (114.93+0.0234) were found to be in maximum quantities as compared to the other extracts. UV/Visible and FTIR scanning results have shown the presence of various significant functional groups. In vitro anti-inflammatory evaluation showed that aqueous extract $(87.46 \%)$ was found to be the most active with $\mathrm{IC}_{50}(570.24 \mathrm{ug} / \mathrm{ml})$ as compared to the reference drug diclofenac sodium. In vitro xanthine oxidase inhibition activity was performed and methanol extract $(88.24 \%)$ found to be the most effective. The findings confirm the plant nutritional value and rationale behind its use in traditional medicine for the treatment of inflammation and gout.
\end{abstract}

Key words: Bryophyllum pinnatum, anti-inflammatory, gout, xanthine oxidase, phytochemical analysis.

\section{INTRODUCTION}

Globally, medicinal plants are extensively used for the cure of various disorders. Drugs obtained from medicinal herbs are low-priced, conveniently accessible and have lesser side effects as compared to the synthetic drugs (Mekuria et al., 2017). Bryophyllum pinnatum (family: Crassulaceae) is also known as Bryophyllum calycinum or Kalanchoe pinnatum (Sadhana et al., 2017). The word "Bryophyllum" is derived from the Greek word which means "sprout leaf" (leaf cuttings can grow) and "pinnatum" is coined from the Latin word which means "quill" (Nagaratna and Hegde, 2015). It is a perennial herb about 3 to 5 meters high and having divergent glabrous leaves (Afzal et al., 2012). It has a sour taste, sugary post digestive effect and hot strength. Herb contains a wide range of valuable chemicals that are responsible for various beneficial therapeutic effects (Jaiswal and Sawhney, 2006; Latif et al., 2019). Bryophyllum pinnatum grows naturally and is native to Madagascar. It is found in temperate regions, including: Asia, Galapagos, Polynesia, New Zealand,
Melanesia,West Indies, the Pacific and Caribbean, Hawaii and Australia (Zamora et al., 1998; Naz et al., 2009).

Several significant therapeutic active constituents and secondary metabolites of plant have been isolated and documented. Among these the most remarkable are flavonoids and bufadienolides (Fürer et al., 2016). The major bufadienolides isolated from the plant leaves are Bryophyllin B and A (Potterat et al., 2013). The herb is an outstanding reserve of vitamins such as niacin, thiamine and ascorbic acid. Minerals are also found in plant which includes: calcium, magnesium, sodium, phosphate, zinc and potassium (Milad et al., 2014).

Worldwide, Bryophyllum pinnatum is used for the treatment of conjunctivitis, edema, cholera, cuts, eczema, piles, chest colds, epilepsy, constipation, asthma, chicken pox, menstrual disorders, and fever (Majaz et al., 2011a). It is frequently used for the cure and management of blisters, burns, cough suppression, rheumatoid arthritis, psychiatric disorders, insect bites and abdominal discomforts. Moreover, it acts as a tocolytic agent to 
prevent premature labor (Gupta et al., 2016; Sadhana et al., 2017) and also employed for the treatment of leg edema, gout, fever, otitis, abscesses and palpitations (Afzal et al., 2012).

This study is aimed to investigate the phytochemical composition of the plant root extracts and in vitro anti-inflammatory and xanthine oxidase inhibition effects. The roots were selected because there is little scientific documentation on them and there is also need to explore the therapeutic value of the plant (Majaz et al., 2011).

\section{MATERIALS AND METHODS}

Plant material and extraction: Bryophyllum pinnatum whole plants were collected in July, 2017 (Figure 1). The plants were obtained from the botanical garden of University of the Punjab, Lahore, Pakistan and identified by taxonomist Prof. Dr. Zaheer-ud-Din Khan, Department of Botany, Government College University (GCU) Lahore, Pakistan. A specimen was deposited in a GCU herbarium (after authentication, voucher no. 3369 was issued). The roots were separated from the plant (Figure 2), cleaned and then dried at the room temperature under the shade for 20-25 days. The dried roots were then crushed into fine powder and stored in airtight plastic bag. Sequential extraction was carried out by using Soxhlet. During the extraction procedure, solvents of different polarity (n-hexane, chloroform, methanol and water) were used. Keeping the temperature less than the boiling point of the respective solvent, all extracts were dried by using a rotary evaporator except aqueous extract which was dried by freeze drying. All extracts were collected in clean, tarred and labeled bottles, and allowed to dry in oven at $40{ }^{\circ} \mathrm{C}$.

Chemicals: Aluminum nitrate crystals, Bovine serum albumin, Chloroform, Copper sulphate, Glucose, Methanol sodium bicarbonate, Sodium hydroxide, Potassium tartrate (Merck, Germany), Gallic acid (Sinochem, China), n-Hexane (BDH, England), Quercitrin (Sigma life sciences, Germany), Anthrone reagent (Sigma life sciences, Germany), Folin and Ciocalteu's phenol reagent (Unichem Chemicals, Ireland), Triton X (Unichem chemicals, Ireland), Allopurinol TCI (Tokyo Chemical Industry), DMSO (Reagent Densen), Xanthine oxidase (Sigma).

Proximate analysis: The total ash, acid soluble ash, water insoluble ash, sulphated ash, moisture content and alcohol and water soluble extractive values were determined according to standard procedures (USP 2015).

Phytochemical analysis: Bryophyllum pinnatum root powder and extracts were evaluated for the levels of metabolites (primary and secondary metabolites). These were estimated by the standard methods described as: total proteins (Lowry et al., 1951), total lipids (Besbes et al., 2004), carbohydrates (Al-Hooti et al., 1998), total polyphenols (Slinkard and Singleton, 1977), total flavonoids (Chang et al., 2002), total polysaccharides and total glycosaponins (Hussain et al., 2008).

Mineral content analysis: Atomic absorption spectroscopy and flame photometer were used to determine the mineral content of the plant. $20 \% \mathrm{w} / \mathrm{v}$ nitric acid was employed to clean volumetric flasks and then rinsed with deionized water. $1 \mathrm{~g}$ of root powder was taken into the beaker. The sample was treated with $15 \mathrm{ml}$ of digestion mixture which comprised of concentrated nitric acid and hydrochloric acid in 1:3 (v/v). The mixture was heated in fuming hood till no more smoke appeared. At room temperature, contents were cooled and filtered. Deionized water was used to make a final volume up to $100 \mathrm{ml}$ and stored in a stoppered bottle for analysis. Analysis of the digested sample was carried out by using the atomic absorption spectrophotometer and flame photometer. Working solution of standard (concentrations; 0, 1, 5, 10, 15, 20, 25 and $100 \mathrm{ppm}$ ) was prepared from standard stock solution (1000 ppm). The tests were performed in triplicates and concentrations of minerals in the sample were determined by the standard plot (Ahmad et al., 2014).

UV/Vis spectroscopy: Extracts stock solutions $(1 \mathrm{mg} / \mathrm{ml})$ were prepared in methanol for the UV/Vis scanning. Methanol was added in stock solution to make the volume up to $10 \mathrm{ml}$ and the same solvent was used as blank. In UV/Vis region (200-800 nm) scans were taken and for each extract maximum wave length $\left(\lambda_{\max }\right)$ was recorded.

FTIR spectroscopy: Root powder and extracts were subjected to FTIR analysis for the purposes of standardization. Material (1mg) was mixed with $100 \mathrm{mg}$ of potassium bromide $(\mathrm{KBr})$. Then the mixture was transferred to die which was compressed in a hydraulic press to prepare the pellets. FTIR spectra were obtained in the range $4000-400 \mathrm{~cm}^{-1}$ (Pavia et al., 2008).

In vitro anti-inflammatory activity: In vitro antiinflammatory potential of extracts was determined by the protein denaturation method. The reaction mixture $(5 \mathrm{ml})$

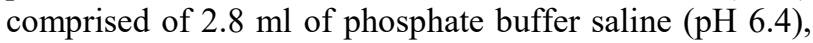
egg albumin (from fresh hen's egg) $0.2 \mathrm{ml}$ and $2 \mathrm{ml}$ of the extracts $(1 \%)$. Control composed of a similar volume of water (double distilled). Mixtures were incubated for 15 minutes at the temperature $37 \pm 2{ }^{\circ} \mathrm{C}$ and then heated for five minutes at temperature $70{ }^{\circ} \mathrm{C}$. After cooling the mixtures, absorbance was measured at $660 \mathrm{~nm}$ wave length by using the vehicle as a blank. Diclofenac sodium and aspirin were used as the standard drugs and treated likewise. Percentage inhibition of protein denaturation was calculated by the following formula: 
$\%$ Inhibition $=\left(\mathrm{A}_{\text {control }}-\mathrm{A}_{\text {test }} / \mathrm{A}_{\text {control }}\right) \times 100$

Where, $\mathrm{A}$ is the absorbance.

$50 \%$ inhibition $\left(\mathrm{IC}_{50}\right)$ of the most active extract and reference drug was determined through the plotting dose response curve by regression line equation where $\mathrm{y}=50$ (Alhakmani et al., 2013).

In vitro xanthine oxidase inhibition activity: In vitro xanthine oxidase inhibition assay was used to evaluate anti-gout potential of the plant. To prepare plant extract solution, extract ( $2 \mathrm{mg}$ ) was dissolved in $1 \mathrm{ml} 5 \%$ DMSO in water solution. In this mixture, $2.9 \mathrm{ml}$ phosphate buffer (1.15 M, pH=7.5) and $0.1 \mathrm{ml}$ of xanthine oxidase enzyme solution (purchased from Sigma) were added. After 15 minutes of mixture pre incubation at $25{ }^{\circ} \mathrm{C}$ temperature, the reaction was started by adding a substrate solution ( 2 $\mathrm{ml}$ ). Then after 30 minutes, the reaction was stopped by adding $1 \mathrm{ml}$ of $\mathrm{IN} \mathrm{HCl}$. Absorbance was measured at $290 \mathrm{~nm}$. Likewise, blank was prepared but enzyme was being added to assay mixture after addition of the $\mathrm{HCl}$. Xanthine oxidase activity was calculated by following formula and expressed as the percentage inhibition of xanthine oxidase.

$\%$ Inhibition of xanthine oxidase $=1-(\mathrm{A}$ extract $/ \mathrm{A}$ no extract) $\mathrm{x} 100$

Where,

A is the absorbance (Guerrero et al., 2011).

\section{RESULTS AND DISCUSSION}

Proximate analysis: Proximate analysis was done for standardization of the root powder. The findings of the analysis are summarized in Table 1.

Table 1. Proximate analysis of Bryophyllum pinnatum root powder.

\begin{tabular}{cc} 
Physicochemical property & Contents (\% w/w) \\
\hline Moisture Content & 6.25 \\
Total Ash & 13 \\
Acid soluble ash & 4 \\
Water insoluble ash & 9.5 \\
Sulphated ash & 16.75 \\
Water soluble extractives & 12.75 \\
Alcohol soluble extractives & 10.5
\end{tabular}

The moisture content was determined according to the USP 2015 prescribed method for botanical origin. The testing of moisture content is an important physicochemical parameter. Moisture content should be less so that the powder may be stable for a longer period of the time. The moisture content of the plant under investigation was found to be within specified range which is not greater than $14 \% \mathrm{w} / \mathrm{w}$ (Munir et al., 2014). Ash value testing is of great significance to identify the presence of any foreign matter like silica, oxalate etc. To evaluate the quality, purity and polarity of the root powder different ash values and extractive values were estimated. The total ash value of the plant under test was found to be $13 \%$ which indicates it is within official range (less than 20\%) (Kadam et al., 2012). High alcohol and water soluble values have suggested the presence of polar substances like tannins, phenols, glycosides etc. (Baravalia et al., 2011).

Phytochemical analysis: Phytochemical analysis comprised of primary and secondary metabolites estimation. The primary metabolites evaluation included: total proteins, total lipids and total carbohydrates and their content are shown in Table 2. Assessment of the secondary metabolites was included: total polyphenols, total polysaccharides, total flavonoids and total glycosaponins and the outcomes of which is summarized in Table 3.

Evaluation of the primary metabolites has revealed that the plant root powder contained varied amount of carbohydrates, lipids and proteins. Current findings have suggested that the carbohydrates were present in larger amount than lipids and proteins. Occurrence of the primary metabolites has indicated substantial nutritional value of the plant (Odhav et al., 2007).

\section{Table 2. Estimation of primary metabolites.}

\begin{tabular}{cc}
\hline Primary metabolite & \% Content $(\% \mathbf{\%} / \mathbf{w})$ \\
\hline Total protein & $21.06 \pm 0.6$ \\
Total lipids & $1.32 \pm 0.001$ \\
Total carbohydrates & $48.54 \pm 0.6$ \\
\hline
\end{tabular}

Table 3. Estimation of secondary metabolites.

\begin{tabular}{lcccc}
\hline \multicolumn{1}{c}{ Extracts } & $\begin{array}{c}\text { Total Polyphenols } \\
(\mathbf{m g} / \mathbf{g})\end{array}$ & $\begin{array}{c}\text { Total Flavonoids } \\
(\mathbf{m g} / \mathbf{g})\end{array}$ & $\begin{array}{c}\text { Total Glycosaponins } \\
(\mathbf{m g} / \mathbf{g})\end{array}$ & Total Polysaccharides (mg/g) \\
\hline n-Hexane & $1.96 \pm 0.014$ & $1.36 \pm 0.016$ & $4.9 \pm 0.018$ & $15.4 \pm 0.023$ \\
Chloroform & $10.93 \pm 0.017$ & $6.72 \pm 0.001$ & $18.9 \pm 0.192$ & $34.1 \pm 0.039$ \\
Methanol & $103.84 \pm 0.022$ & $95.81 \pm 0.026$ & $39.9 \pm 0.103$ & $100.7 \pm 0.008$ \\
Water & $114.93 \pm 0.034$ & $76.11 \pm 0.03$ & $24.8 \pm 0.035$ & $139.4 \pm 0.026$ \\
\hline
\end{tabular}

Analyses of extracts' secondary metabolites have proven that the roots of Bryophyllum pinnatum contained the polyphenols in larger amount in aqueous extract while the n-hexane has the lowest value. 
Appreciable amounts of polyphenols were present in methanol extract as well. Total flavonoids were present in highest amounts in the methanol extract while $n$-hexane has the lowest quantity. Methanol extract has high quantity of glycosaponins while n-hexane has shown the minimum value. In aqueous extract, polysaccharides were found to be in abundance when compared to the others. Before the recognition of their significance in science, secondary metabolites were thought to be the surplus product of the plants. Later, their worth was recognized and it was determined that these metabolites play a crucial role (Verpoorte, 1998). Variety of secondary metabolites chemicals library was produced by the medicinal plants that displayed the inclusive array of the therapeutic effects and biological activities (Wink, 2015). Polyphenols constitute one of the diverse and abundant group of the secondary metabolites which displayed noticeable anti-inflammatory i.e. provide shielding against the arthritis (Bravo, 1998), anti-tumors, gout reduction (Oliviero et al., 2018) and cardiovascular protective effects (Manach et al., 2005). Phenolic contents were found in considerable amount and could serve as a natural source of potential anti-oxidant (Dudonné et al., 2009). It has been recognized that the flavonoids are quite proficient against inflammation and also have anti-cancer properties (Middleton et al., 2000). The presence of the glycosaponins in the plant has indicated that medicinal herb possesses hemolytic activity (Okwu and Okwu, 2004). Scientific studies have shown that saponins exhibit anti-microbial, anti-tussive, immunomodulation and anti-diabetic properties (Upadhyay et al., 2018).

Mineral content analysis: The mineral content analysis has revealed the presence of various important minerals in the plant (Table 4).

Table 4. Mineral content analysis of Bryophyllum pinnatum roots

\begin{tabular}{cc}
\hline Element & Quantity (\%) \\
\hline $\mathbf{F e}$ & 2.4 \\
$\mathbf{C u}$ & 0.01 \\
$\mathbf{C r}$ & 0.004 \\
$\mathbf{Z n}$ & 0.0074 \\
$\mathbf{P b}$ & 0.0026 \\
$\mathbf{M g}$ & 0.81 \\
$\mathbf{M n}$ & 0.036 \\
$\mathbf{P}$ & 0.025 \\
$\mathbf{N a}$ & 0.174 \\
$\mathbf{K}$ & 0.41 \\
$\mathbf{C a}$ & 7.18 \\
\hline
\end{tabular}

Results have indicated that the plant is a rich source of the valuable minerals. Sample of root powder contains the maximum amount of sodium, potassium, phosphorous, zinc, copper, calcium and iron. Deficiency of the minerals in the human body may lead to various pathological conditions (Gharibzahedi and Jafari, 2017). Calcium is a ubiquitous macro element that is found in plants. Calcium plays a crucial role in blood coagulation and wound healing (Okwu and Josiah, 2006). Phosphorous is also a macronutrient. It is associated with the nucleic acid synthesis and hence essential for the plant growth (Schachtman et al., 1998). Potassium helps in reducing high blood pressure (Whelton et al., 1997). Magnesium is an important component of plant chlorophyll (Szulc and Waligóra, 2010) and iron is vital for the production of hemoglobin (Laurell, 1952). Presence of zinc indicates that plant may be helpful in the treatment of diabetes (Okaka and Okaka, 2001).

UV Visible scanning: The findings (Figure 3) indicate that lambda maximum for all extracts were present between the range 200-300 nm. n-hexane, chloroform, methanol and water have a maximum peak at the wavelength of $210 \mathrm{~nm}, 262 \mathrm{~nm}, 257 \mathrm{~nm}$ and $231 \mathrm{~nm}$ respectively. These scans suggest the presence of secondary metabolites i.e. polyphenols, flavonoids etc. (Gierschner et al., 2012).

FTIR scanning: FTIR spectra of Bryophyllum pinnatum root powder (Figure 4) show a strong and broad peak at the $3275.1 \mathrm{~cm}^{-1}$ (OH stretching and H-bonded) which indicates the presence of alcohol and phenols. Peaks between $3000-2850 \mathrm{~cm}^{-1}$ indicate the presence of alkanes (medium, C-H stretch). At the $1735.0 \mathrm{~cm}^{-1}$ there is $\mathrm{C}=\mathrm{O}$ stretch which showed the presence of esters and saturated aliphatic functional groups. Peak at the $1606.2 \mathrm{~cm}^{-1}$ showed the presence of an aromatic group (C-C stretch). Peaks between the range of the $1320-1000 \mathrm{~cm}^{-1}$ (strong, C-O stretch) indicate the presence of alcohol, carboxylic acids, esters and ethers. Extracts overlay (Figure 5) has exhibited the presence of alkanes, hydroxyl and aromatic groups. The presence of various functional groups has suggested that the plant is enriched with various bioactive chemicals i.e. flavonoids, polyphenols etc.

In vitro anti-inflammatory activity: The in vitro antiinflammatory activity and $\mathrm{IC}_{50}$ of the most active extract were investigated against the protein denaturation of the egg albumin and outcomes are summarized in Table 5 and Table 6 respectively.

Table 5. In vitro anti inflammatory activity assessment of root extracts of Brypohyllum pinnatum.

\begin{tabular}{ll}
\hline Standard/etracts & \% Inhibition \\
\hline Control & - \\
Standard Diclofenac & $94.85 \pm 0.06$ \\
Standard Aspirin & $85.38 \pm 0.38$ \\
n-hexane extract & $23.71 \pm 0.12$ \\
Chloroform extract & $20.27 \pm 0.06$ \\
\hline
\end{tabular}




\begin{tabular}{ccc}
\hline $\begin{array}{l}\text { Methanol extract } \\
\text { Water extract }\end{array}$ & $\begin{array}{c}40.06 \pm 0.1 \\
87.67 \pm 0.69\end{array}$ \\
\hline Table 6. IC $_{\mathbf{5 0}}$ of diclofenac and aqueous extract (most \\
active) against protein denaturation. \\
\multicolumn{3}{c}{} \\
\hline Concentration & Diclofenac & Water extract \\
(ug/ml) & (\% inhibition) & (\% inhibition) \\
\hline Control & - & - \\
62.5 & 11.23 & 6.0 \\
125 & 35.08 & 12.46 \\
250 & 44.92 & 24.62 \\
500 & 52.15 & 64.92 \\
1000 & 68.46 & 70.77 \\
\hline
\end{tabular}

The anti-denaturation egg albumin method was adopted to evaluate the anti-inflammatory activity of Bryophyllum pinnatum. Results (Figure 6) show that the aqueous extract has the highest value of percentage inhibition $(87.46 \%)$, while chloroform extract has the lowest value of percentage inhibition (20.27\%). The antiinflammatory effect of aqueous extract is less than the standard drug diclofenac $(94.85 \%)$ but is greater than the aspirin $(84.96 \%)$. Percentage of inhibition of protein denaturation is actually the measure of protein stabilization against the control. Reference drug diclofenac and aqueous extract exhibited marked reduction in protein denaturation. Comparative evaluation of $\mathrm{IC}_{50}$ (Figure 7) reveals that the water extract $\left(\mathrm{IC}_{50}=570.24 \mathrm{ug} / \mathrm{ml}\right)$ effect was greater than the reference drug, diclofenac $\left(\mathrm{IC}_{50}=625.24 \mathrm{ug} / \mathrm{ml}\right)$ (Chandra et al., 2012). These findings have shown a concentration dependent inhibition of protein denaturation by the aqueous root extract and standard drug (diclofenac). The current investigation has confirmed anti-inflammatory activity of the plant and can therefore be helpful in the

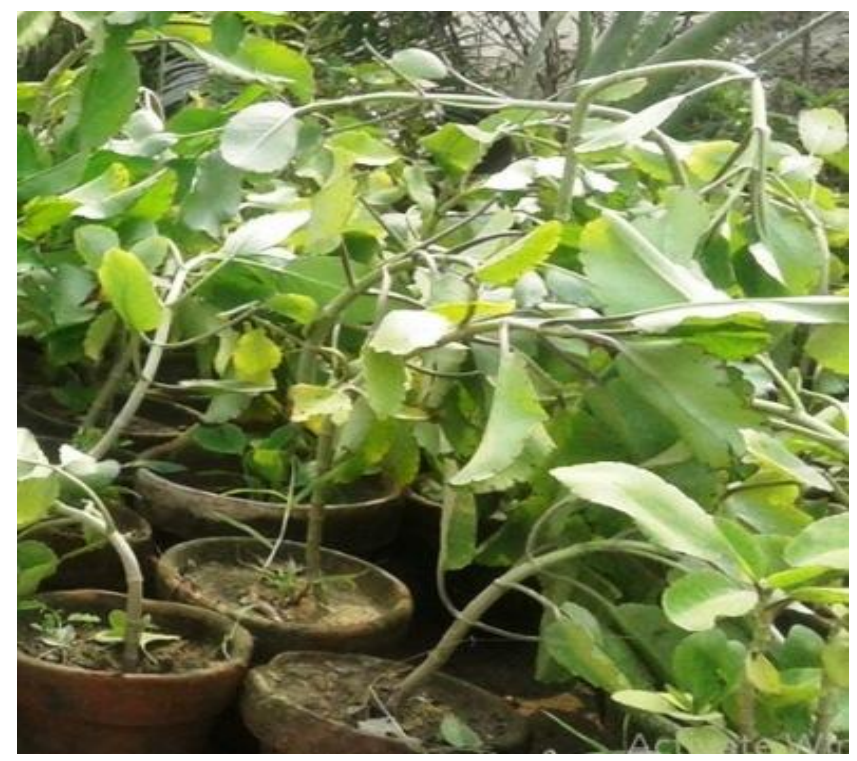

Figure 1. Bryophyllum pinnatum plant treatment of inflammatory conditions. The antiinflammatory activity of the plant may be related with the presence of high phenolic contents (Alhakmani et al., 2013).

In vitro xanthine oxidase inhibition activity: Outcomes of the assay is summarized in Table 7 and demonstrated in Figure 8.

Table 7. \% inhibition of xanthine oxidase of root extracts of Bryophyllum pinnatum

\begin{tabular}{ll}
\hline Standard/extracts & \% inhibition of xanthine oxidase \\
\hline Control & - \\
n-Hexane & $7.34 \pm 0.002$ \\
Chloroform & $31.54 \pm 0.005$ \\
Methanol & $88.30 \pm 0.004$ \\
Water & $44.22 \pm 0.04$ \\
Standard & $97.1 \pm 0.002$
\end{tabular}

The in vitro xanthine oxidase inhibition model was used. Results have shown that the methanol extract has significant ability to inhibit the xanthine oxidase activity but the value of percentage inhibition is less than that of the allopurinol. Drugs that impede the activity of xanthine oxidase are helpful for the treatment of gout and liver ailments (Ashiq et al., 2018). Xanthine oxidase belongs to the class of flavoprotein that transforms xanthine into uric acid and yields free radicals (Sahgal et al., 2009). These findings have shown that the methanol extract has blocking effect on the xanthine oxidase and hence beneficial for the treatment and management of gout. Phytochemicals i.e. polyphenols, flavonoids and saponins are useful to lessen the levels of uric acid in serum (An et al., 2010).

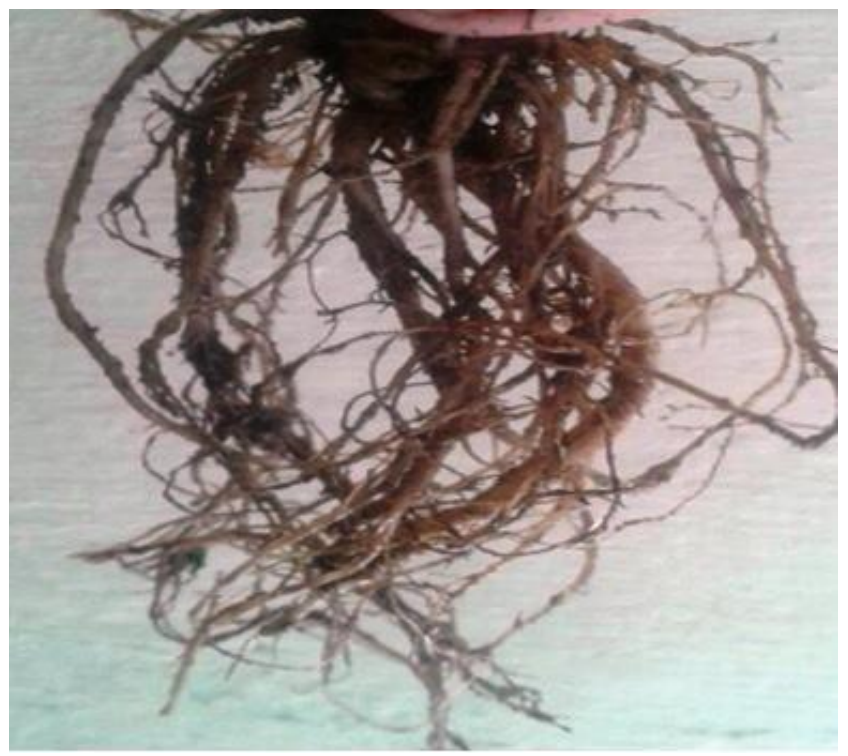

Figure 2. Bryophyllum pinnatum plant roots 


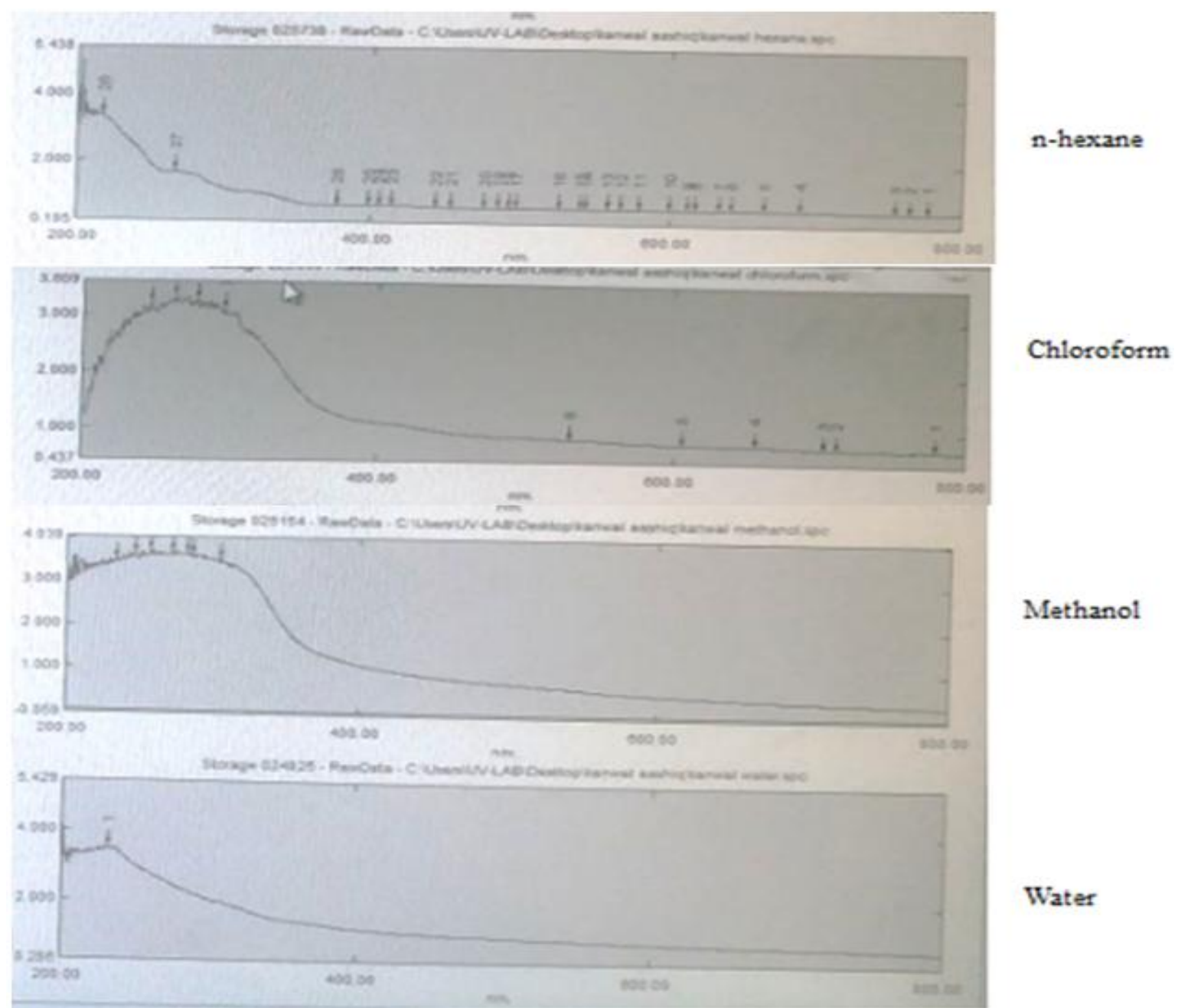

Figure 3. UV Visible spectra of n-hexane, chloroform, methanol and water

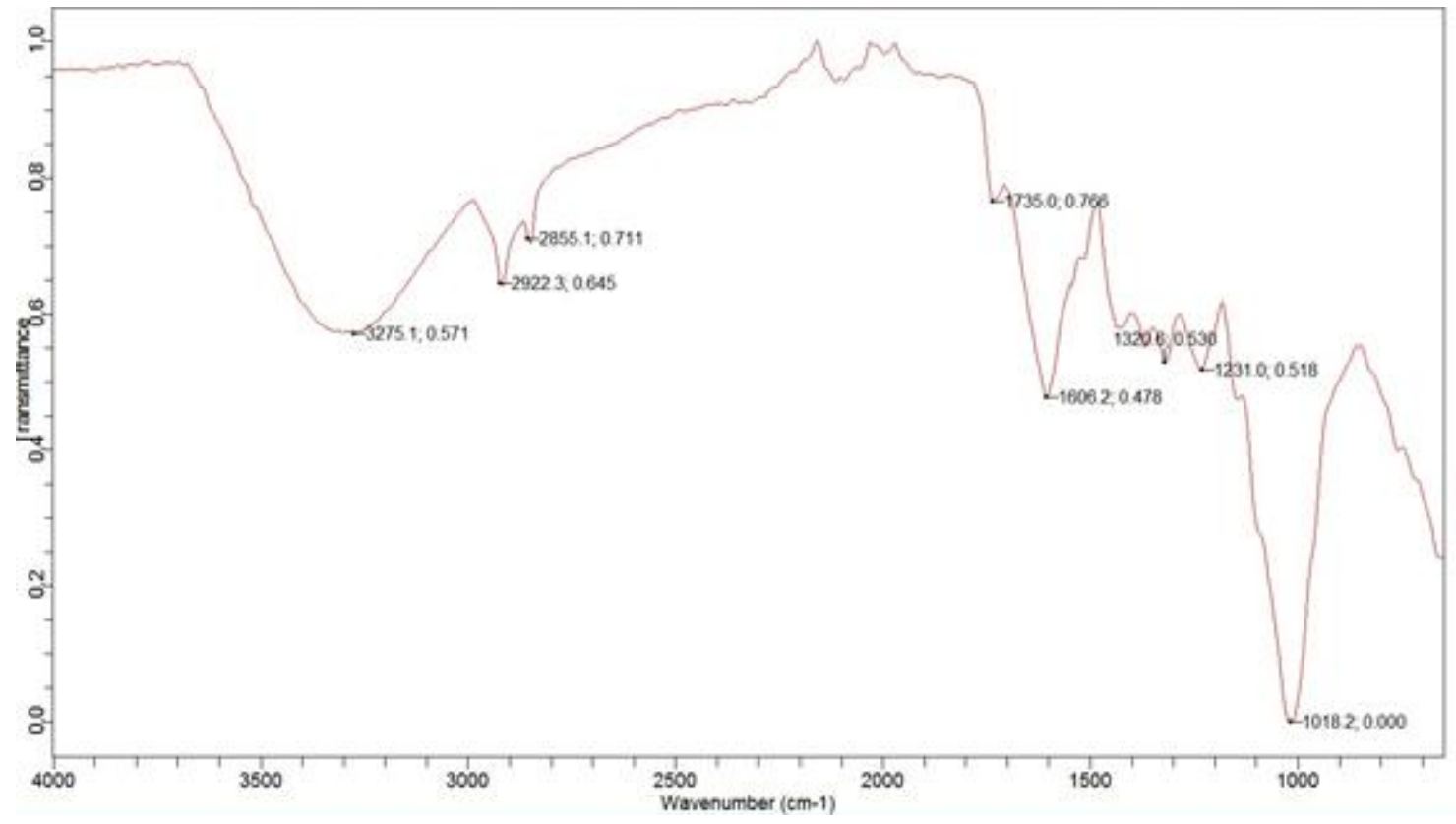


Figure 4. FTIR scan of root powder of Bryophyllum pinnatum

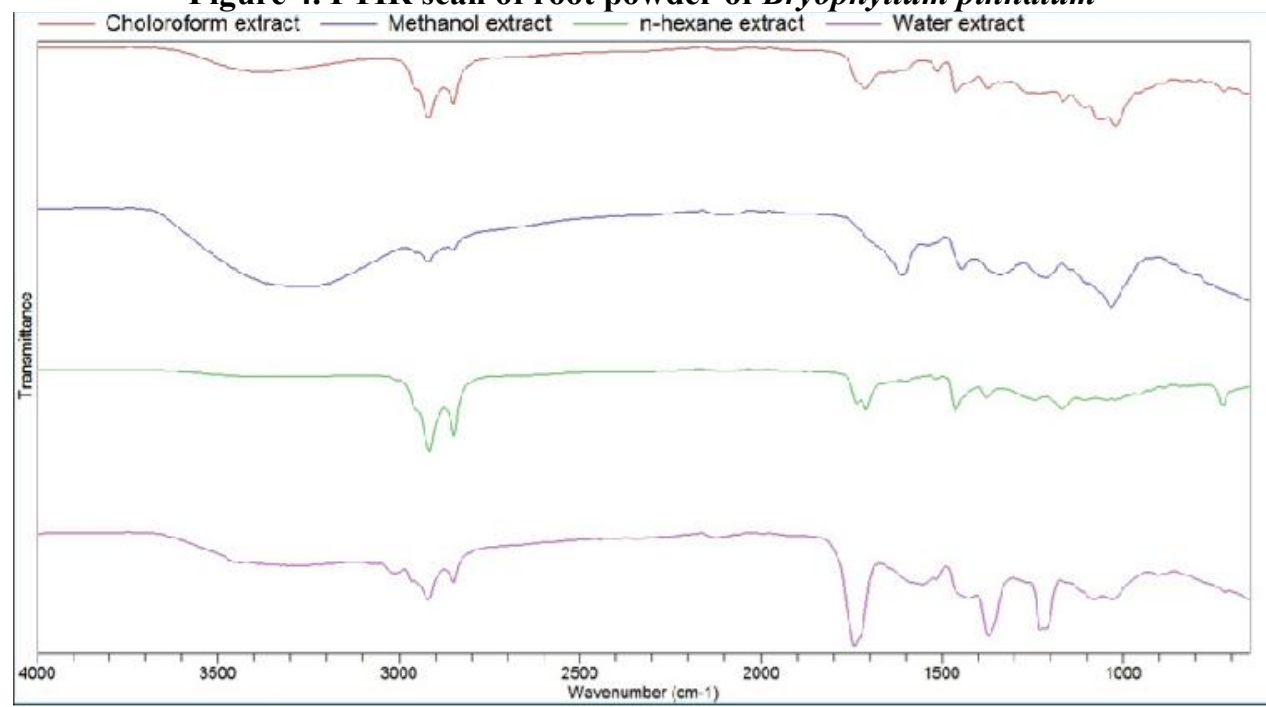

Figure 5. FTIR scan overlay of root extracts of Bryophyllum pinnatum

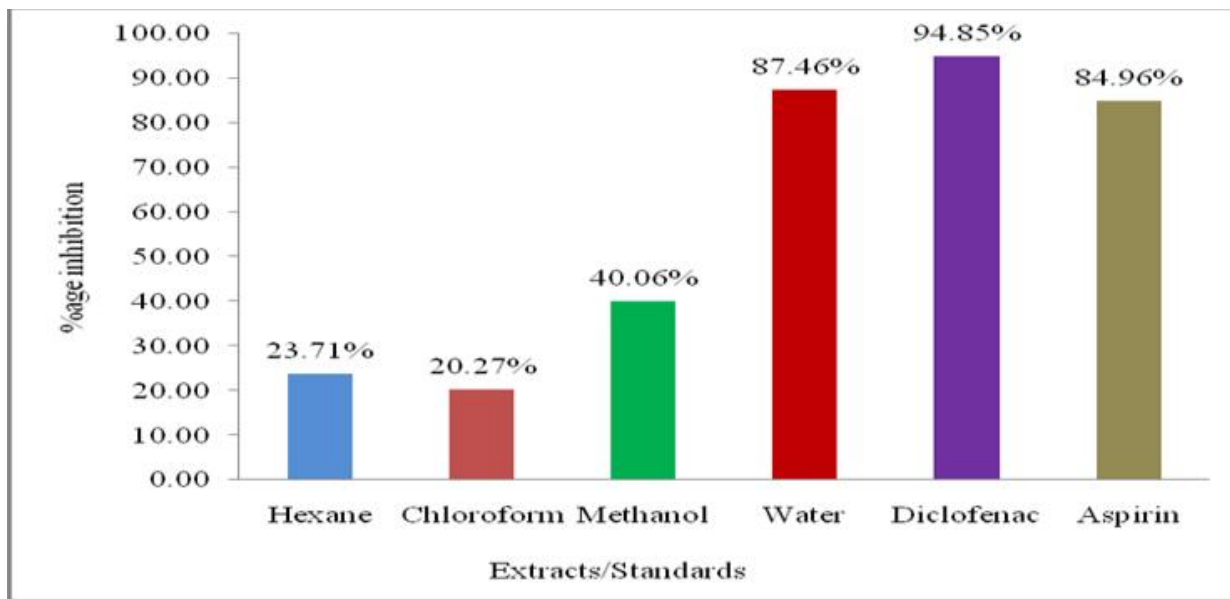

Figure 6. In vitro anti inflammatory activity evaluation of root extractsof Brypohyllum pinnatum

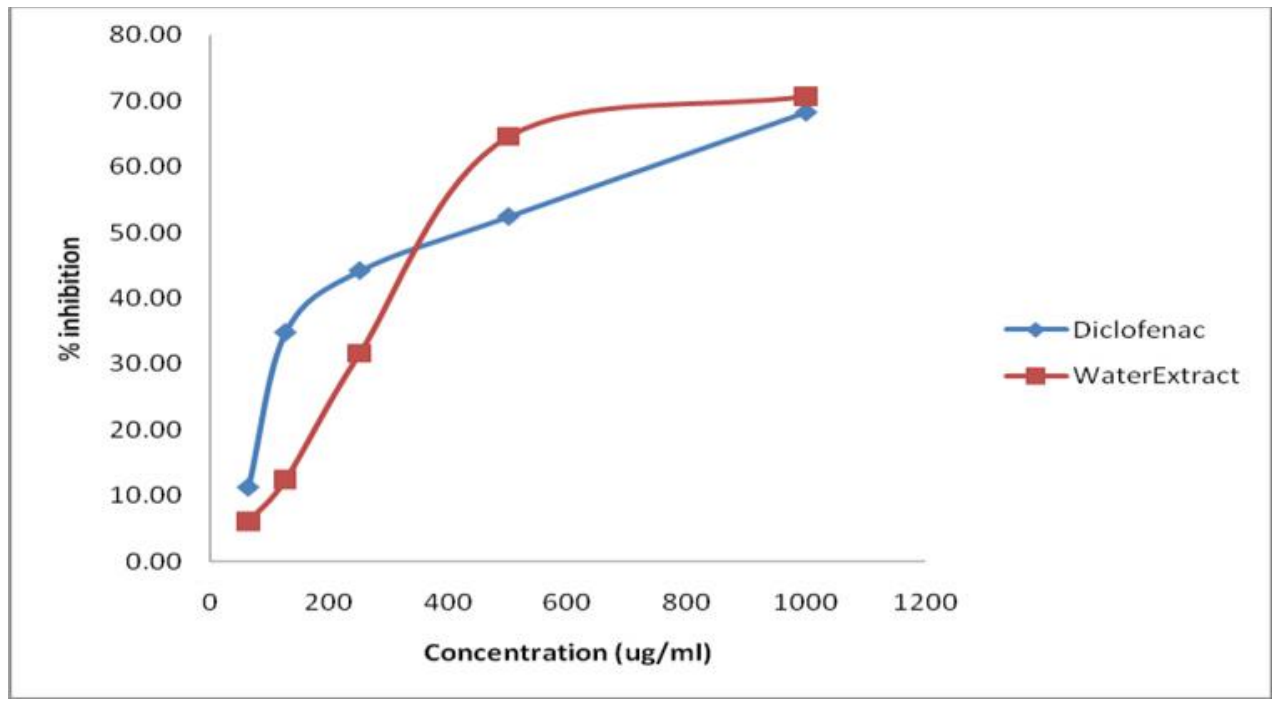

Figure 7. Comparison between $\mathrm{IC}_{50}$ of diclofenac and water extract 


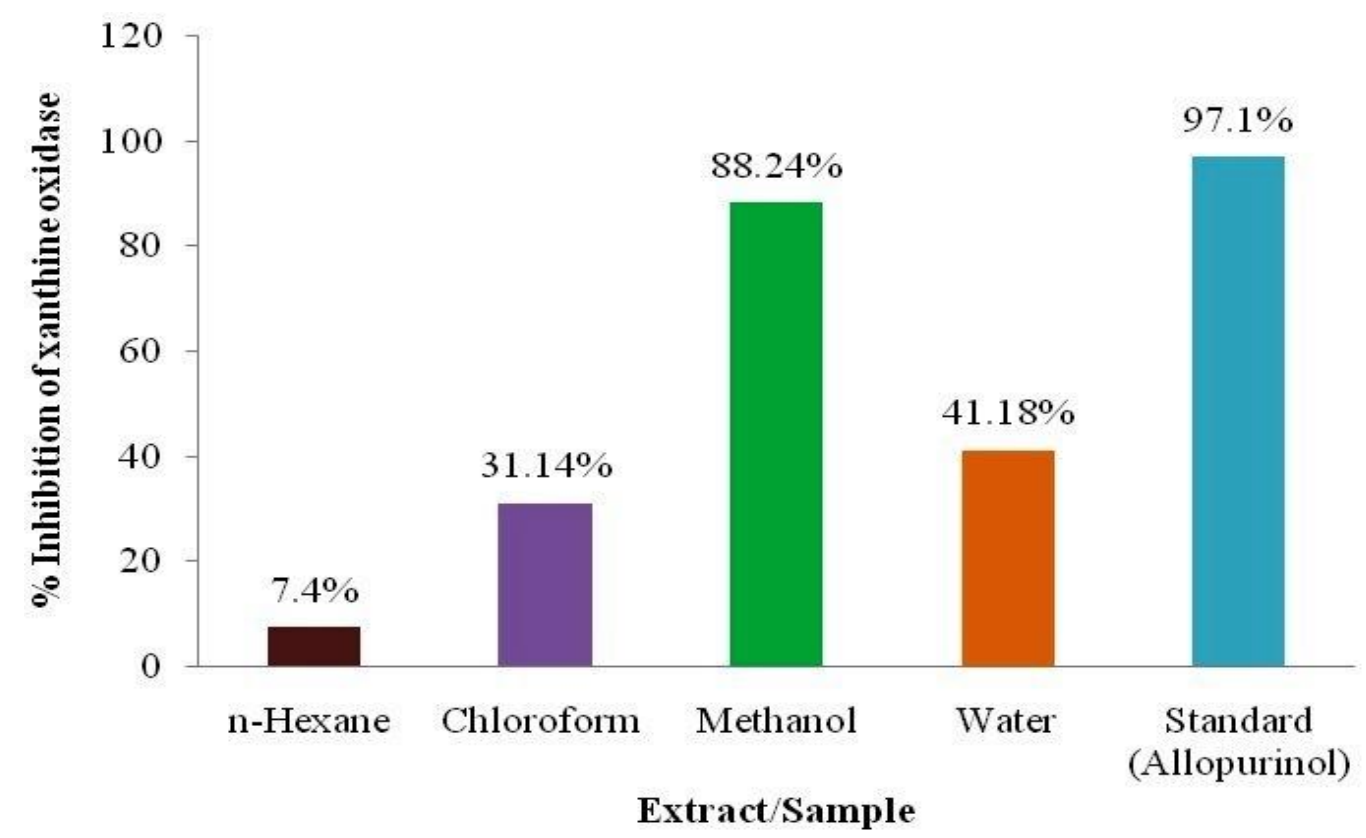

Figure 8. \% inhibition of xanthine oxidase by root extracts of Bryophyllum pinnatum

Conclusion: The findings of current study show that the Bryophyllum pinnatum has potential effects against inflammation and gout. Moreover, the plant contains a significant amount of the important phytochemicals which are responsible for various pharmacological activities. The plant is enriched with various minerals that play vital roles in different physiological functions. There are however, needs for further studies to ascertain its safety and justify its efficacy.

Acknowledgments: The authors would like to acknowledge University College of Pharmacy, University of the Punjab, Lahore, Pakistan and Faculty of Pharmaceutical Sciences, Superior University Lahore, Pakistan for their kind support.

Disclosure of conflict of interest: There is no conflict of interest among authors.

\section{REFERENCES}

Afzal, M., I. Kazmi, R. Khan, R. Singh, M. Chauhan, T. Bisht, and F. Anwar (2012). "Bryophyllum pinnatum: a review." Int. J. Res. Biol. Sci. 2(4): 143-149.

Ahmad, A., A. Husain, M. Mujeeb, N. A. Siddiqui, Z. A. Damanhouri, and A. Bhandari (2014). Physicochemical and phytochemical standardization with HPTLC fingerprinting of Nigella sativa L. seeds. Pakistan J. Pharm. Sci. 27(5): 1175-1182.

Alhakmani, F., S. Kumar, and S.A. Khan (2013). Estimation of total phenolic content, in-vitro antioxidant and anti-inflammatory activity of flowers of Moringa oleifera. Asian. Pac. J. Trop. Biomed. 3(8): 623-627.

Al-Hooti, S., S. Sidhu, and H. Gabazard (1998). Chemical composition of seeds of date fruit cultivars of United Arab Emirates. J. Food Sci. Technol. 35(1): 44-46.

An, J., H.-J. Yang, K. Park, J. Lee, and B.-W. Kim (2010). Reparatory and preventive effects of oriental herb extract mixture (OHEM) on hyperuricemia and gout. Food Sci. Biotechnol. 19(2): 517-524.

Ashiq K., A. Latif, S. Ashiq, and A. Sundus (2018). A systematic review on the prevalence, pathophysiology, diagnosis, management and treatment of gout (2007-2018). GSC. Biol. Pharm. Sci. 5(1): 50-55.

Baravalia, Y., K. Nagani, and S. Chanda (2011). Evaluation of pharmacognostic and physicochemical parameters of Woodfordia fruticosa Kurz. flowers. Pharmacog. J. 2(18): 13-18.

Besbes, S., C. Blecker, C. Deroanne, N.-E. Drira, and H. Attia (2004). Date seeds: chemical composition and characteristic profiles of the lipid fraction. Food Chem. 84(4): 577-584.

Bravo, L. (1998). Polyphenols: chemistry, dietary sources, metabolism, and nutritional significance. Nutr. Rev. 56(11): 317-333.

Chandra, S., P. Chatterjee, P. Dey, and S. Bhattacharya (2012). Evaluation of in vitro anti-inflammatory activity of coffee against the denaturation of protein. Asian. Pac. J. Trop. Biomed. 2(1): S178-S180. 
Chang, C.-C., M.-H. Yang, H.-M. Wen, and J.-C. Chern (2002). Estimation of total flavonoid content in propolis by two complementary colorimetric methods. J. Food. Drug. Anal. 10(3): 178-182.

Dudonné, S., X. Vitrac, P. Coutiere, M. Woillez, and J.M. Mérillon (2009). Comparative study of antioxidant properties and total phenolic content of 30 plant extracts of industrial interest using DPPH, ABTS, FRAP, SOD, and ORAC assays. J. Agric. Food. Chem. 57(5): 1768-1774.

Fürer, K., A. P. Simões-Wüst, U. von Mandach, M. Hamburger, and O. Potterat (2016). Bryophyllum pinnatum and related species used in anthroposophic medicine: constituents, pharmacological activities, and clinical efficacy. Planta. Med. 82(11/12): 930-941.

Gharibzahedi, S. M. T., and S. M. Jafari (2017). The importance of minerals in human nutrition: Bioavailability, food fortification, processing effects and nanoencapsulation. Trends. Food. Sci. Technol. 62: 119-132.

Gierschner, J., J.-L. Duroux, and P. Trouillas (2012). UV/Visible spectra of natural polyphenols: a time-dependent density functional theory study. Food Chem. 131(1): 79-89.

Guerrero, R. O., S. M. Rivera, S. Rivera, and L. A. Sueiro (2011). Bioassay screening of Amazonian plants. P. R. Health.Sci. J. 22(3): 291-297.

Gupta, S., S. Adak, R. C. Rajak, and R. Banerjee (2016). In vitro efficacy of Bryophyllum pinnatum leaf extracts as potent therapeutics. Prep. Biochem. Biotechnol. 46(5): 489-494.

Hussain, K., Z. Ismail, A. Sadikun, and P. Ibrahim (2008). Analysis of proteins, polysaccharides, glycosaponins contents of Piper sarmentosum Roxb. and anti-TB evaluation for bioenhancing/interaction effects of leaf extracts with Isoniazid (INH). Nat. Prod, Rad. 7(5): 402408.

Jaiswal, S., and S. Sawhney (2006). Correlation of epiphyllous bud differentiation with foliar senescence in crassulacean succulent Kalanchoe pinnata as revealed by thidiazuron and ethrel application. J. Plant. Physiol. 163(7): 717-722.

Kadam, P. V., K. N. Yadav, A. N. Patel, V. S. Navsare, S. K. Bhilwade, and M. J. Patil (2012). Phytopharmacopoeial specifications of Garcinia indica fruit rinds. Phcog. J. 4(31): 23-28.

Latif, A., K. Ashiq, M. Qayyum, S. Ashiq, E. Ali, and I. Anwer (2019). Phytochemical and pharmacological profile of the medicinal herb: Bryophyllum pinnatum. The J. Anim. Plant Sci. 29 (6): 1528-1534

Laurell, C. B., (1952). Plasma iron and the transport of iron in the organism. Pharmacol. Rev. 4(4): 371395.
Lowry, O. H., N. J. Rosebrough, A. L. Farr, and R. J. Randall (1951). Protein measurement with the Folin phenol reagent. J. Biol. Chem. 193(1): 265-275.

Majaz, Q. A., A. Tatiya, M. Khurshid, S. Nazim, and S. Siraj (2011a). The miracle plant (Kalanchoe pinnata): a phytochemical and pharmacological review. Int. J. Res. Ayurveda. Pharm. 2(5): 1478-1482.

Majaz, Q., S. Nazim, S. Shaikh, P. Gomase, and A. Choudhari (2011). Phytochemical analysis of chloroform extract of roots of Kalanchoe pinnata by HPLC and GCMS. Int. J. Pharm. Sci. Res. 2: 1693-1699.

Manach, C., G. Williamson, C. Morand, A. Scalbert, and C. Rémésy (2005). Bioavailability and bioefficacy of polyphenols in humans. I. Review of 97 bioavailability studies. Am. J. Clin. Nutr. 81(1): 230S-242S.

Mekuria, A. B., D.A. Erku, B.M. Gebresillassie, E.M. Birru, B. Tizazu, and A. Ahmedin (2017). Prevalence and associated factors of herbal medicine use among pregnant women on antenatal care follow-up at University of Gondar referral and teaching hospital, Ethiopia: a crosssectional study. BMC. Complement. Altern. Med. 17(1): 86.

Middleton, E., C. Kandaswami, and T. C. Theoharides (2000). The effects of plant flavonoids on mammalian cells: implications for inflammation, heart disease, and cancer. Pharmacol. Rev. 52(4): 673-751.

Milad, R., S. El-Ahmady, and A. N. Singab (2014). Genus Kalanchoe (Crassulaceae): A Review of Its Ethnomedicinal, Botanical, Chemical and Pharmacological Properties. European. J. Med. Plants. 4(1):86-104.

Munir, U., A. Perveen, and S. Qamarunnisa (2014). Comparative Pharmacognostic evaluation of some species of the genera Suaeda and Salsola leaf (Chenopodiaceae). Pakistan J. Pharm. Sci. 27(5): 1309-1315.

Nagaratna, A., and P. L. Hegde (2015). A comprehensive review on Parnabeeja [Bryophyllum pinnatum (Lam.) Oken]. J. Med. Plants. Stud. 3(5): 166171.

Naz, S., J. Sumera, I. Saiqa, and A. Ali (2009). An efficient protocol for rapid multiplication of Bryophyllum pinnatum and Bryophyllum daigremontianum. Pakistan J. Bot. 41(5): 23472355.

Odhav, B., S. Beekrum, U. Akula, and H. Baijnath (2007). Preliminary assessment of nutritional value of traditional leafy vegetables in KwaZulu-Natal, South Africa. J. Food Compos. Anal. 20(5): 430-435. 
Okaka, J., and A. Okaka (2001). Food composition, spoilage and shelf life extension. OCJANCO Acad. Publishers, Enugu, Nigeria: 225-226.

Okwu, D. E., and C. Josiah (2006). Evaluation of the chemical composition of two Nigerian medicinal plants. Afr. J. Biotechnol. 5(4): 357-361.

Okwu, D., and M. Okwu (2004). Chemical composition of Spondias mombin Linn plant parts. J. Sustain. Agric. Environ. 6(2): 140-147.

Oliviero, F., A. Scanu, Y. Zamudio-Cuevas, L. Punzi, and P. Spinella (2018). Anti-inflammatory effects of polyphenols in arthritis. J. Sci. Food. Agric. 98(5): 1653-1659.

Pavia, D. L., G. M. Lampman, G. S. Kriz, and J. A. Vyvyan (2008). Introduction to spectroscopy, Cengage Learning.

Potterat, O., M. Gerodetti, M. Oufir, K. Fürer, M. Mennet-von Eiff, R. Brenneisen, U. von Mandach, and M. Hamburger (2013). Quantification by UPLC-MRM ESIMS of bufadienolides in Bryophyllum pinnatum leaves and manufactured products. Planta. Med. 79(13): 30 .

Sadhana, D., S. Parveen, N.1 Bukhari, N. Shehzadi, S. Qamar, A. Ijaz, S.U. Niazi, S. Naheed, A. Latif, and K. Hussain (2017). Bryophyllum pinnatum: botanical description, vernacular names, parts used, traditional uses, phytochemical and phrmacological activities. Pakistan J. Pharm. 30(1): 3-9.

Sahgal, G., S. Ramanathan, S. Sasidharan, M. N. Mordi, S. Ismail, and S. M. Mansor (2009). In vitro antioxidant and xanthine oxidase inhibitory activities of methanolic Swietenia mahagoni seed extracts. Molecules. 14(11): 4476-4485.

Schachtman, D. P., R. J. Reid, and S. M. Ayling (1998). Phosphorus uptake by plants: from soil to cell. Plant. Physiol. 116(2): 447-453.
Slinkard, K., and V. L. Singleton (1977). Total phenol analysis: automation and comparison with manual methods. Am. J. Enol. Vitic. 28(1): 4955.

Szulc, P., and H. Waligóra (2010). Response of maize hybrid (Zea mays L.), stay-green type to fertilization with nitrogen, sulphur, and magnesium. Part I. Yields and chemical composition. Acta Sci. Pol. 9(1): 29-40.

Upadhyay, S., G. S. Jeena, and R. K. Shukla (2018). Recent advances in steroidal saponins biosynthesis and in vitro production. Planta. 248(3): 519-544.

USP (2015). United States Pharmacopoeia Drug Information for the Health Care Professional. Thomas PDR. Micromedex. 1.

Verpoorte, R. (1998). Exploration of nature's chemodiversity: the role of secondary metabolites as leads in drug development. Drug Discov. Today. 3(5): 232-238.

Whelton, P. K., J. He, J. A. Cutler, F. L. Brancati, L. J. Appel, D. Follmann, and M. J. Klag (1997). Effects of oral potassium on blood pressure: meta-analysis of randomized controlled clinical trials. JAMA. 277(20): 1624-1632.

Wink, M. (2015). Modes of action of herbal medicines and plant secondary metabolites. Medicines. 2(3): 251-286.

Zamora, A.B., S.S. Gruezo, and S.V. Siar (1998). Somaclonal variation: Breeder's tool for recovering potential cultivars in ornamentals (Kalanchoe). 14. Annual Scientific Conference of the federation of Crop Science Societies of the Philippines, Cebu City (Philippines), 19-24 April. 